\title{
POWER CONSUMPTION IN ROOM (SPLIT) AIRCONDITIONING USING ALTERNATIVE REFRIGERANT R-600a
}

\author{
Bhabaranjan Sarmah ${ }^{1}$ \\ ${ }^{1}$ Assam Engineering Institute, Guwahati, Assam
}

\begin{abstract}
In this age of rapid economic development India is in need of huge of amount of energy including electricity. The prohibitive cost of setting up of new facilities for production of electricity led to the introduction of various means for saving electricity at every front. Airconditioners are huge consumers of electricity. So, reduction in use of electricity in airconditioner could be very much beneficial to the cause of the nation. At the same time all measures are being taken to save the environment from the hazards of global warming producing chemicals and burning of fossil fuels. All these purposes could be met by introduction of hydrocarbon refrigerants like Isobutane $(R-600 a)$. As such in the present work tests have been conducted to measure the saving in electrical energy when the existing-22 gas (refrigerant) is replaced by $R-600$ a as refrigerant in the same system. It is found that substantial saving could be achieved in the consumption of electricity by this replacement without compromising the basic cooling effect. However, the flammability factor of R-600a is to be properly taken care of.
\end{abstract}

Keywords: refrigerant, alternative, electricity, consumption, isobutane, Montreal protocol, ozone depletion, global warming, flammability

\section{INTRODUCTION}

Airconditioners are huge consumer of electricity. Hence many research works are going on to explore the possibility of reducing the energy consumption to some extent.

Annual air conditioner sales in the EU are expected to grow from 4.9 million units in 2005 to almost 10 million by 2020 . At the same time the stock will increase from around 40 million units to 110 million installed air conditioners [Riviere et al,2009]

Power generation in India began more than a century ago in 1898 when the first hydro power unit was set up at Darjeeling. When India achieved freedom in 1947, the country had an installed capacity of 1,360 MW. But as of September 2012, The electricity sector in India has an installed capacity of 207.85 Terawatt (TW), the world's fifth largest [Central Electricity Authority, GOI, 2012].

Though the achievement is sizeable, but considering the rapid development that are taking place in India, it will have to achieve within next 10 years more than what it achieved in last seven decades.

Energy is the indispensible part of development. The limited energy access is reflected,(as shown in Figure 1.1 below), in the relatively low Human Development Index of India.[MoEF, GOI]

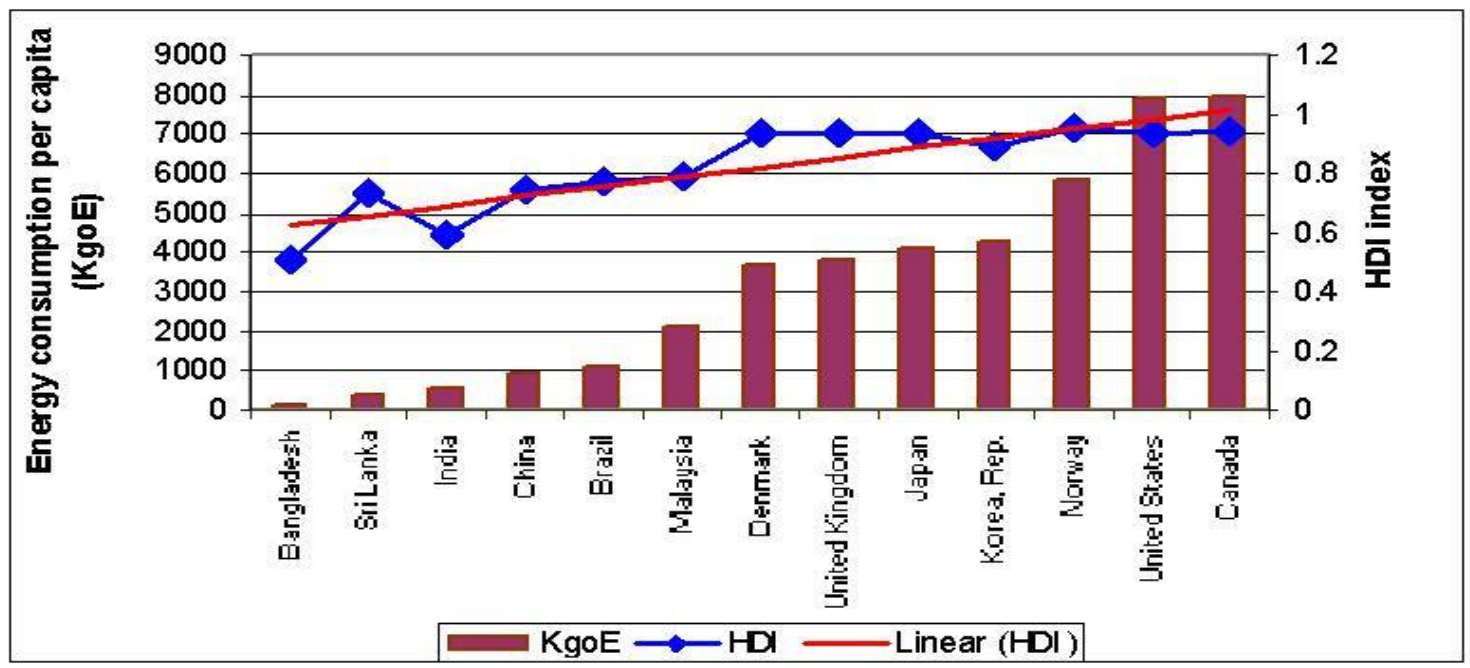

Fig. 1.1 Energy consumption is a prime driver of the Human Development Index. [source: MoEF,GOI] 


\section{LITERATURE SURVEY}

Literature survey was done to find the previous research in this field.

Farzad et al,1993 experimented the effect of expansion device on airconditioners system performance characteristics.

Rodriguez,1995 mentioned different tests of effects of ambient temperature, evaporator airflow rate etc and also conducted two tests on effect of refrigerant charge by changing the amount of charge on 3 ton and 3.5 ton airconditioners

Chris Neme et al 1999. discussed the possibility of saving energy in residential airconditioners by solving problems of installation of these units, where they specially focused on four factors viz. equipment sizing, refrigerant charging, ensuring adequate airflow and sealing ducts properly. They concluded that proper installation, servicing and maintenance can improve $17 \%$ energy efficiency.

Shen et al, 2006 described the impact of non uniform refrigerant mass flow in evaporator of airconditioner using R-410A and R-407C as refrigerants.

Kopecka et al, 2013, tested the performance and efficiency of airconditioners using alternative refrigerants.[85a]

\section{R-600a AS ALTERNATIVE REFRIGERANT}

Use of freons as refrigerant is to be stopped mainly due to their adverse effect of depletion of ozone gas in the atmosphere. CFC gas in refrigerators has already been stopped before $1^{\text {st }}$ January,2010. However the HCFC gas is allowed as refrigerant of airconditioners till 2030 due to its comparatively less harmful affect on ozone [table 1.1].

Albert Einstein actually came up with the idea of an ecofriendly refrigerator and patented one in 1930s with his colleague Leo Szillard. The design was partly used in the first domestic refrigerators, but the technology was abandoned when more efficient compressors became popular in the 1950s. The refrigerator patented by Einstein and Szilard's did not use freons.

The refrigerant which is being used in room airconditioners extensively since $1950 \mathrm{~s}$ is hydro-chloro-flouro-carbon (HCFC) or commonly called as R-22. However, one MoU among almost all the countries in the world signed on $16^{\text {th }}$ September,1987 at Montreal, Canada and known as Montreal Protocol decided to permanently stop use of R-22. This is done to save the ozone layer of the Earth, which is the protective layer around the earth lying at 10 to $50 \mathrm{~km}$ above earth surface and protecting the earth from the harmful UV-B rays of the sunlight.

As a result of Montreal Protocol (1987) and subsequent Meeting of Parties (2007), all HCFC refrigerants including the most common refrigerant R-22 are going to be replaced by alternatives and R-22 will be completely stopped by 2030. The phase of reduction of production of HCFC refrigerant is shown in Fig1.2 Project HPMP (HCFC Phaseout Management Plan) under Ministry of Environment and Forestry, govt. of India and being implemented all over the country with support from GTZ, Germany (Gesellschaft fur Internationale Zusammenerbeit)

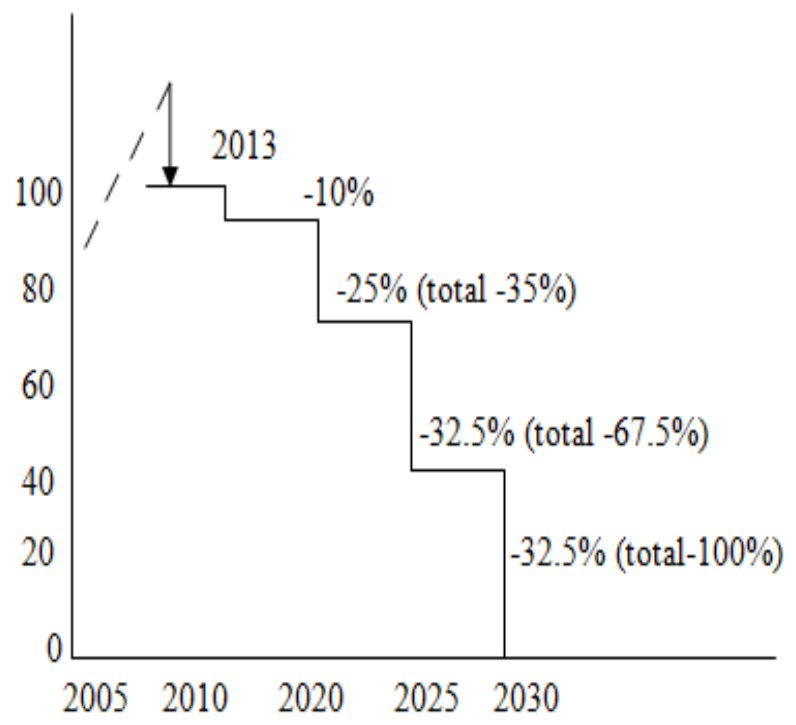

Fig. 1.2 Reduction of production of HCFC by year (base year 2009-10)

As the production of R-22 began to reduce as per Montreal Protocol, from 2013 and likely to be completely stopped by 2030 as shown in Fig. 8.1, there is hectic search for a good alternative to R-22.

Many alternatives are being experimented around the world. The main alternatives are in the group HFC (hydro-fluorocarbon) and HC (hydro carbon). Though some other alternatives like $\mathrm{CO} 2$, air etc are also in the list but due some technical reasons, the alternative refrigerants in the HFC and $\mathrm{HC}$ groups are experimented more seriously and some are already being used by many manufacturers.In the HFC group the widely experimented and used refrigerants are R$410 \mathrm{~A}, \mathrm{R}-407 \mathrm{C}, \mathrm{R}-404 \mathrm{~A}$ etc. In the HC category the refrigerants, which are under consideration are R-600a, R290 etc.

While selecting an alternative refrigerant, apart from the performance of the refrigerant in the system, their Ozone Depleting Potential and Global Warming Potential are also taken into consideration. However, under Montreal Protocol, the first priority is to remove all chemicals (read refrigerants) having ODP. The list of different alternative refrigerant with their ODP and GWP are shown in table 1.1. 
Table 1.1 Ozone depletion Potential (ODP) and Global Warming Potential (GWP) of different Refrigerants (source: HPMP slides)

\begin{tabular}{|c|l|c|c|c|}
\hline \multicolumn{2}{|c|}{ Refrigerant } & $\begin{array}{c}\text { Atmospheric } \\
\text { Lifetime (Years) }\end{array}$ & ODP & $\begin{array}{c}\text { GWP (100 } \\
\text { Year) }\end{array}$ \\
\hline CFC & $\begin{array}{l}\text { CFC-11 } \\
\text { (Baseline ODP) }\end{array}$ & 50 & 1 & 4000 \\
\hline & CFC-12 & 102 & 1 & 8500 \\
\hline CFC Blend & R-502 & & 0.33 & $\mathbf{5 2 6 0}$ \\
\hline HCFCs & HCFC-22 & 13.3 & $\mathbf{0 . 0 5 5}$ & $\mathbf{1 7 0 0}$ \\
\hline & HCFC-123 & 1.4 & $\mathbf{0 . 0 2}$ & $\mathbf{9 3}$ \\
\hline & HCFC-141b & 9.4 & $\mathbf{0 . 1 1}$ & $\mathbf{6 3 0}$ \\
\hline HFCs & HFC-134a & 14.6 & 0 & 1300 \\
\hline & HFC-152a & 1.4 & 0 & 120 \\
\hline & HFC-245fa & 7.3 & 0 & $\mathbf{8 2 0}$ \\
\hline Natural Fluids & HC-290 (Propane) & - & 0 & 3 \\
\hline & HC-600a (Isobutane) & - & 0 & 3 \\
\hline & HC blend & - & 0 & 3 \\
\hline & R-744 Carbon & - & 0 & 1 \\
\hline & Dinxide & - & 0 & 3260 \\
\hline HFC Blends & R-404A & - & 0 & 1770 \\
\hline & R-407A & - & 0 & 1530 \\
\hline & R-407C & - & 0 & 1730 \\
\hline & R-410A & &
\end{tabular}

From table 1.1 , it is obvious that hydrocarbon refrigerants like R-290 (propane), R-600a (isobutene) etc. , which are classified as natural refrigerants have ODP zero and very little GWP. Hence from environmental point of view these are very good refrigerants. As such it is decided to test the power consumption pattern of a hydrocarbon refrigerant $\mathrm{R}$ 600a in a split room airconditioner.

Another reason of selecting $\mathrm{HC}$ refrigerant for testing is that the typical charge quantity used in units using hydrocarbon like propane, is approximately $0.10 \mathrm{~kg} \mathrm{~kW}^{-1}$ compared to $0.25 \mathrm{~kg} \mathrm{~kW}^{-1}$ for R-22 [ACRIB,2001]. The reduced amount of refrigerant leads to reduction in energy consumption and at the same time it is environment-friendly.

\section{THE TESTS AND RESULTS}

The tests and their results are given in section 4.1 and 4.2

In this research work a few tests were performed to measure the energy consumption pattern in the same airconditioner in which all tests were done, by changing the refrigerants in different amount.

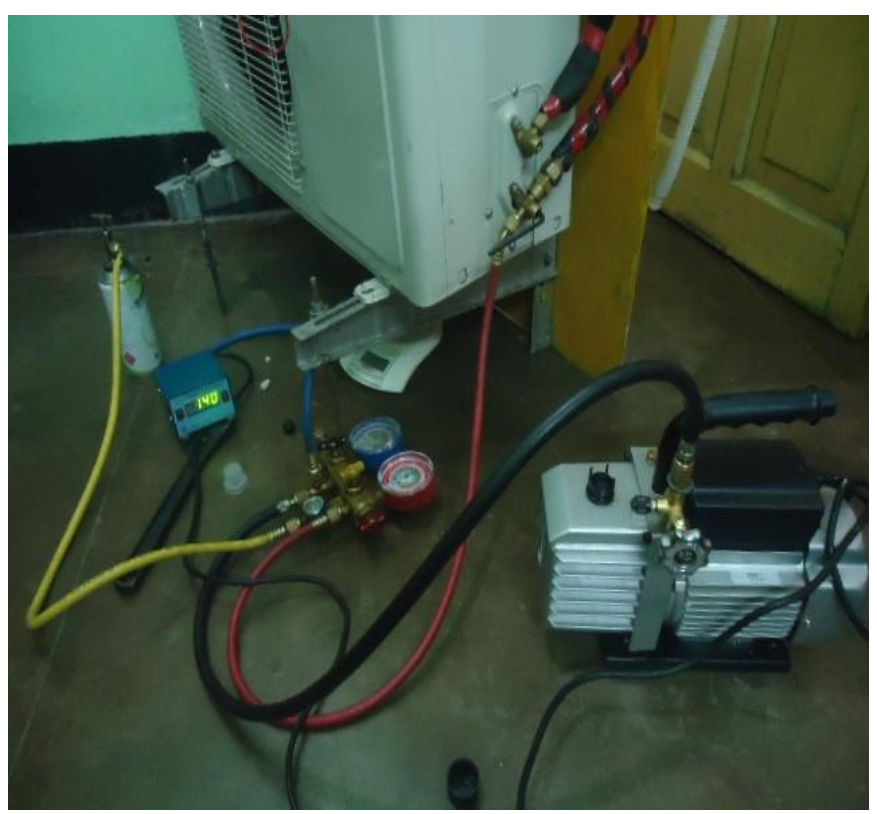

Fig 1.3 Setup for evacuation of the airconditioner and charging R-600a 


\subsection{Tests for Energy Consumption at Different Charges}

At first the refrigerant is changed from R-22 to R-600a, which is a hydrocarbon refrigerant and as such miscible with the mineral oil used with R-22. The amount of hydrocarbon gas is only $40 \%$ of the amount of R-22 [HPMP] and as such $236 \mathrm{gm}(40 \%$ of $590 \mathrm{gm})$ of R-600a is charged in the system.

Before charging the refrigerant R-600a following steps were conducted as per norms.

(i) recovered the existing R-22 refrigerant using recovery machine.

(ii) system is evacuated to 200 micron using two stage rotary vacuum pump with blank-off pressure of 10 micron.
After charging the system with R-600a refrigerant, leak test was done by nitrogen gas of $99.9995 \%$ purity.

Thereafter the connections are made through the wattmeter to the power supply. Thermostat is set at $16^{\circ} \mathrm{C}$. Ambient temperatures are taken as $27^{\circ} \mathrm{C}, 32^{\circ} \mathrm{C}$ and $33.1^{\circ} \mathrm{C}$ to verify its stability.

Though ambient temperatures were maintained with the help of room heaters, but humidity was not controlled as the present work was aimed to study the behaviour of the system at field condition where there will be no humidity control. The ambient temperature variation was kept within $\pm 0.5^{0} \mathrm{C}$.

The results of one set of such test is given in graphical form in Fig.1.4 using R-600a and R-22 as refrigerants
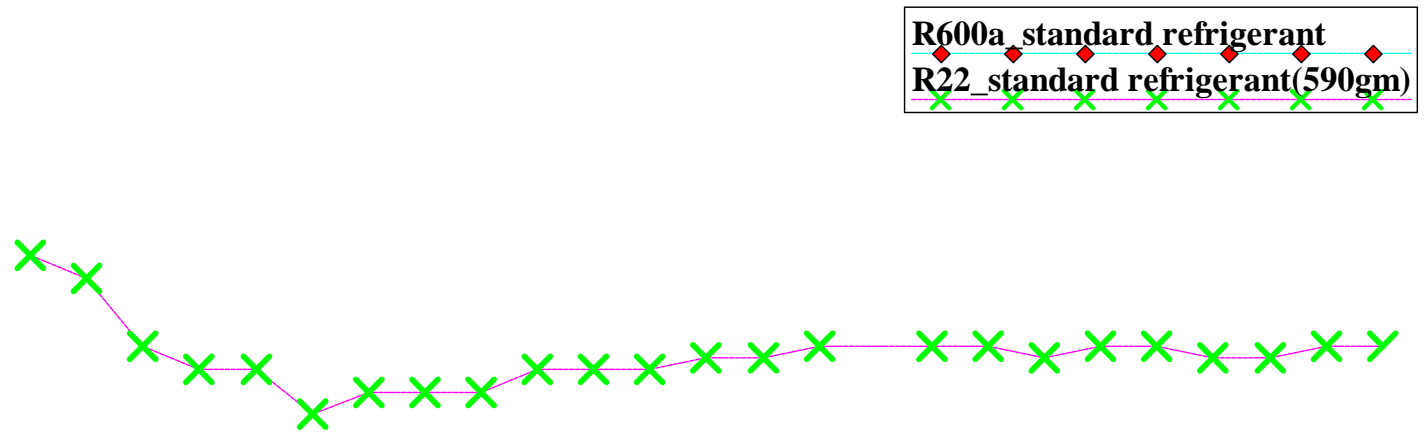

Fig. 1.4 Graph showing the power consumption by split airconditioner with different refrigerant

\subsection{Energy Consumption with R-22 and R-600a as}

\section{Refrigerant in the Same Airconditioner.}

From the graph 1.4 for 8 months (240 days) running @ 8hrs per day,
The power consumption with R22 refrigerant standard (590 gm)

$$
\begin{aligned}
& =241350 \text { Watt.minutes } \\
& =241350 \text { X } 8 / 6 \text { X } 240 / 60000 \\
& =1287 \mathrm{kWHr}
\end{aligned}
$$


The power consumption with R600a $=159604$ watt.minutes (for 6 hours)

$$
\begin{aligned}
& =159604 \times 8 / 6 \mathrm{hrs} \text { X } 240 \text { days } / 60000 \\
& =851 \mathrm{kWHr} \text { per annum }
\end{aligned}
$$

It is observed that power consumption is sufficiently low when R-600a is used as refrigerant. It is safe from environmental point of view as well. However its problem is that being a hydrocarbon it is flammable and so extra care is required while using it as a refrigerant.

\subsection{Cost of Power Consumption in Room ACs}

An estimated 358 million air-cooled air conditioners (cooling and heating) are installed worldwide, [Butrymowicz et al 2005] which is consuming a huge amount of electricity.

Calculating the annual cost of power for an air conditioner:

Air conditioner sizes are often given as "tons" of cooling where 1 ton of cooling is being equivalent to $12,000 \mathrm{BTU} / \mathrm{h}$ $(3.517 \mathrm{~kW})$. This is approximately the power required to melt one ton of ice in 24 hours. The annual cost of electric power consumed by an airconditioning unit may be calculated as follows
From equation 1.1 and graph 1.4 , the cost of electricity and subsequent saving in the use of R-600a can be calculated

Considering 8 hours a day use for 8 months or 240 days a year and the existing tariff of electricity in Guwahati, the cost of consumption are shown below

\section{Using R-22 as Refrigerant}

Energy consumed in 6 hours $=241350$ watt.minutes 241350 watt minute/60000 X 8/6 X 240 X Rs. 5.74/kWHr $=$ Rs.7387 per year

\section{Using R-600a as Refrigerant}

Energy consumed in 6 hours $=159604$ Watt.minutes i.e. $159604 / 60,000 \times 8 / 6$ X 240 days X Rs.5.74 = Rs. 4886 per year

Table 1.2 Difference of consumption and cost in R-22 and R-600a

\begin{tabular}{|l|l|l|}
\hline Refrigerant & $\begin{array}{l}\text { Consumption per } \\
\text { year (kWHr) }\end{array}$ & $\begin{array}{l}\text { Cost of } \\
\text { consumption (Rs.) }\end{array}$ \\
\hline R-22 & 1287 & 7387 \\
\hline R-600a & 851 & 4885 \\
\hline
\end{tabular}

Actual consumption per hour X No of hrs per day

X 240 days per year

$\mathrm{X}$ cost of electrical energy per $\mathrm{kWHr}$

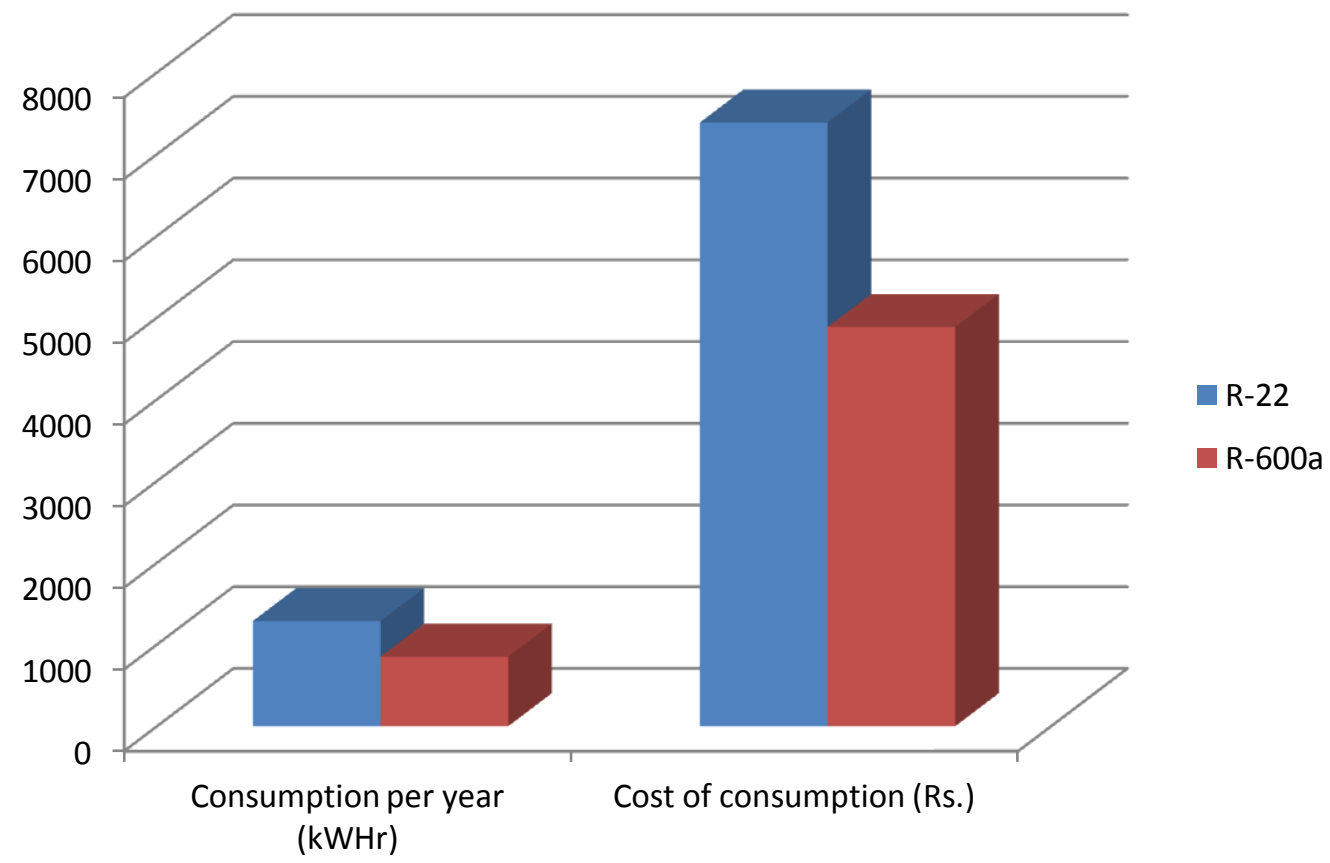

Fig 1.5 Comparative bar diagram showing saving in consumption of electricity and cost

\section{CONCLUSION}

From the above tests it is observed that a substantial amount of energy (and cost) is saved by using R-600a as refrigerant in place of R-22. At the same time it is an environmentfriendly refrigerant, which can be released into the atmosphere without causing any harm to the environment. The performance of cooling is almost same as that with R22. However, the problem is that R-600a, being a hydrocarbon gas is flammable. As such it is not allowed to be used in refrigerators and airconditioners, especially in mobile airconditioners in many European countries. 
But now-a-days many safety features are available to contain this effect.

Since R-600a is compatible with mineral oil, which is used with R-22 as well, so R-600a could be considered seriously as a drop-in substitute for R-22.

Table 1.3 The safety designation (flammability) and GWP (environmental effect)

\begin{tabular}{|l|l|l|}
\hline Refrigerant & $\begin{array}{l}\text { Safety } \\
\text { Designation }\end{array}$ & $\begin{array}{l}\text { GWP(100 } \\
\text { years } \\
\text { horizon })\end{array}$ \\
\hline R600a & A3 & 3 \\
\hline R22 & A1 & 1700 \\
\hline
\end{tabular}

As shown in Table 1.3 the refrigerant R-22 is safe from the point of view of flammability hazard but have high Global warming potential threatening the environment. On the other hand refrigerant R-600a is comparatively safe for the environment (GWP 3 only), but is considered as highly flammable (A3). Hence, the safety features against possibility of fire must be properly taken while using R$600 \mathrm{a}$ as refrigerant.

\section{REFERENCES}

[1] Farzad, Mohsen and Dennis L O’Neal :Inference of the expansion device on airconditioner system performance characteristic under a range of charging conditions ASHRAE Transactions: Research 313(1993)

[2] Angel Gerardo Rodriguez, in his paper Effect Of Refrigerant Charge, Duct Leakage, and Evaporator Air Flow on the High Temperature Performance of Air Conditioners and Heat Pumps, August 1995

[3] Chris Neme, John Proctor, Steven Nadel : Energy saving Potential from addressing residential airconditioner and heat pump installation problem (Feb 1999) published by American council for energy efficient economy(ACEEE)

[4] Bo Shen, James E. Braun, Eckhard A. Groll Some Modeling Improvements for Unitary Air Conditioners and Heat Pumps at Off-Design Conditions International refrigeration and airconditioning Conference, 2006

[5] Butrymowicz Dariusz (Poland), James Crawford (USA), David Godwin (USA), Kenneth Hickman (USA), Fred Keller (USA), Haruo Onishi (Japan): Residential and Commercial Air Conditioning and Heating, IPCC/TEAP Special Report: Safeguarding the Ozone Layer and the Global Climate System [2005]

[6] Philippe Riviere, Jérôme Adnot, Laurent GrignonMasse, Sébastien Legendre, Dominique Marchio et al : Preparatory study on the environmental performance of residential room conditioning appliances (airco and ventilation)

[7] Central Electricity Authority, Ministry of Power, Government of India. June 2012."All India Regionwise Generating Installed Capacity Of Power".
[8] India: Addressing Energy Security And Climate Change by Ministry of Environment \& Forests Ministry of Power, Bureau of Energy Efficiency, Government of India

[9] ACRIB, 2001: Guidelines for the Use of Hydrocarbon Refrigerant in Static Refrigeration and Air-conditioning systems. Air Conditioning and Refrigeration Industry Board, (ACRIB), Carshalton, UK.

[10] Market Kopecka, Michal Hegar, Vladimir Sulc, Jeff Berge drop-in test for refrigerant blend L40 , DR-7 and ARM-30a in a trailer refrigeration unit designed for R-404A ,AHRI Low GWP Refrigerant evaluation programme. 2013 